\title{
Pembuatan Media Informasi Kuliner Kota Medan Berbasis Web Sebagai Sarana Promosi Menggunakan Metode Ucd (User Center Design)
}

\author{
Zevi Adam Maulana*1, Ibnu Rasyid Munthe ${ }^{2}$, Mutia ${ }^{3}$ \\ ${ }^{1,2,3}$ Universitas Labuhan Batu, Rantau Prapat, Indonesia \\ Email : zeviadam01@gmail.com ${ }^{* 1}, \underline{\text { ibnurasyidmunthe@,gmail.com }}{ }^{2}$
}

\begin{abstract}
Abstrak
Kuliner adalah suatu bagian hidup yang erat kaitannya dengan konsumsi makanan sehari-hari. Kuliner merupakan sebuah gaya hidup yang tidak dapat dipisahkan dari kehidupan sehari-hari. Karena setiap orang memerlukan makanan yang sangat dibutuhkan sehari-hari. Mulai dari makanan yang sederhana hingga makanan yang berkelas tinggi dan mewah. Promosi merupakan teknik komunikasi yang secara penggunaannya atau penyampaiannya dengan menggunakan media seperti: pers, televisi, radio, papan nama, poster dan lain-lain yang bertujuannya untuk menarik minat konsumen terhadap hasil produksi suatu perusahaan. Promosi sebagai media untuk menjembatani kepentingan produsen dengan konsumen. UCD (User Centered Design) merupakan paradigma baru dalam pengembangan sistem berbasis web. Perancangan berbasis pengguna (User Centered design $=U$ ser Centered Design $=U C D)$ adalah istilah yang digunakan untuk menggambarkan filosofi perancangan. Konsep dari UCD adalah User sebagai pusat dari proses pengembangan system, dan tujuan sifat-sifat, konteks dan lingkungan system semua didasarkan dari pengalaman pengguna. PHP adalah bahasa pemrograman server side yang sudah banyak digunakan pada saat ini, terutama untuk pembuatan website dinamis. Untuk hal-hal tertentu dalam pembuatan web, bahasa pemrograman PHP memang diperlukan, misalnya saja untuk memproses data yang dikirimkan oleh pengunjung web.
\end{abstract}

Kata kunci : UCD (User Centered Design) , PHP

\begin{abstract}
Culinary is a part of life that is closely related to the consumption of food everyday. Culinary is a lifestyle that can not be separated from everyday life. Because everyone needs food that is needed everyday. Starting from simple food to high-class and luxurious food. Promotion is a communication technique that use or delivery by using media such as: press, television, radio, signboard, posters and others whose purpose is to attract consumers to the production of a company. Promotion as a medium to bridge the interests of producers with consumers. UCD (User Centered Design) is a new paradigm in developing web based system. User Centered Design (UCD) is a term used to describe design philosophy. The concept of UCD is the User as the center of the system development process, and the objectives of the system's nature, context and environment are all based on user experience. PHP is a server side programming language that has been widely used at this time, especially for the creation of dynamic websites. For certain things in making the web, PHP programming language is necessary, for example, to process the data sent by web visitors.
\end{abstract}

Keywords : UCD (User Centered Design) , PHP 


\section{PENDAhUluan}

Medan merupakan kota terbesar nomor 3 setelah Jakarta dan Surabaya, kota Medan merupakan ibukota dari provinsi sumatera utara yang dikenali dengan khas batak nya, karena disumatera utara suku yang dominan adalah suku batak. Kehidupan di kota medan tidak jauh berbeda dengan dikota besar lainnya dengan banyaknya suku dan etnis berbeda tentunya menambah warna kehidupan di kota medan terutama masalah kuliner atau identic dengan makanan(Iqbal \& Rosnelly, 2020).

Makanan di kota medan terkenal dengan ciri khas pedas dan asam manis, para penjual kuliner di kota medan mulai aktif dari siang hari sampai malam hari terutama café-café dengan harga yang lumayan mahal atau juga makanan pinggir jalan dengan rasa yang enak tapi dengan harga murah. Banyaknya kuliner di kota medan menjadi pilihan bagi penikmat kuliner yang ingin merasakan masakan yang berbeda.

Soto medan, bolu meranti, pancake medan merupakan beberapa jenis kuliner kota medan yang wajib dicicipi jika berada di kota medan, bagi masyarakat kota medan mungkin makanan tersebut sudah biasa tapi bagi masyarakat luar yang berkunjung ke Medan wajib mencoba masakan-masakan tersebut dan masakan lain yang merupakan ciri khas kota medan.

Kuliner adalah suatu bagian hidup yang erat kaitannya dengan konsumsi makanan sehari-hari. Kuliner merupakan sebuah gaya hidup yang tidak dapat dipisahkan dari kehidupan sehari-hari. Karena setiap orang memerlukan makanan yang sangat dibutuhkan sehari-hari. Mulai dari makanan yang sederhana hingga makanan yang berkelas tinggi dan mewah.

Kuliner adalah hasil olahan yang berupa masakan. Masakan tersebut berupa lauk pauk, makanan (penganan), dan minuman(Mikrokontroler et al., 2020). Karena setiap daerah memiliki cita rasa tersendiri, maka tak heran jika setiap daerah memiliki tradisi kuliner yang berbeda beda. Contohnya kota medan memiliki masakan kuliner seperti soto medan(Zulfikar \& Lukman, 2016)

UCD (User Center Design) adalah sebuah filosofi perancangan yang menempatkan pengguna sebagai pusat dari sebuah proses pengembangan sistem. Kesulitan pengguna (end user) selama ini untuk membaca dan menerjemahkan dokumen-dokumen yang ada dalam setiap pengembangan dapat terbantu menggunakan metode User Center Design . Teknik ,metode ,tools, prosedur dan proses yang membantu perancangan sistem interaktif dibangun berdasarkan pengalaman pengguna. User Center Design adalah menerjemahkan partisipasi dan pengalaman manusia ke perancangan(Fau et al., 2017)

User merupakan objek yang penting didalam pengembangan dan pembangun sistem .User disini adalah pribadi,organisasi, dan masyarakat. User saat ini harus berada pada level of design sophistication dari semua antar muka grafis beserta isi webnya. Pada saat user berinteraksi dengan sistem user harus merasa sesuai dengan pengalaman yang pernah dirasakan dengan informasi yang disediakan oleh sistem dan merasa nyaman saat berintraksi dengan sistem(Fricles Ariwisanto Sianturi, Jonson Manurung, 2020).

UCD (User Centered Design) merupakan paradigma baru dalam pengembangan sistem berbasis web. Perancangan berbasis pengguna (User Centered design $=$ User Centered Design $=$ UCD) adalah istilah yang digunakan untuk menggambarkan filosofi perancangan.Konsep dari UCD adalah User sebagai pusat dari proses pengembangan system, dan tujuan sifat-sifat, konteks dan lingkungan system semua didasarkan dari pengalaman pengguna(Fricles Ariwisanto Sianturi, 2013).

Promosi merupakan teknik komunikasi yang secara penggunaannya atau penyampaiannya dengan menggunakan media seperti: pers, televisi, radio, papan nama, poster dan lain-lain yang bertujuannya untuk menarik minat konsumen terhadap hasil produksi suatu perusahaan. Promosi sebagai media untuk menjembatani kepentingan produsen dengan konsumen(Butarbutar et al., 2020).

PHP adalah bahasa pemrograman server side yang sudah banyak digunakan pada saat ini, terutama untuk pembuatan website dinamis. Untuk hal-hal tertentu dalam pembuatan web, 
bahasa pemrograman PHP memang diperlukan, misalnya saja untuk memproses data yang dikirimkan oleh pengunjung web.

\section{METODE PENELITIAN}

\section{UCD (User Centered Design)}

UCD (User Center Design) adalah sebuah filosofi perancangan yang menempatkan pengguna sebagai pusat dari sebuah proses pengembangan system. Kesulitan pengguna (end user) selama ini untuk membaca dan menerjemahkan dokumen-dokumen yang ada dalam setiap pengembangan dapat terbantu menggunakan metode User Center Design(Banjarnahor \& Lim, 2020) . Teknik ,metode, tools, prosedur dan proses yang membantu perancangan sistem interaktif dibangun berdasarkan pengalaman pengguna. User Center Design adalah menerjemahkan partisipasi dan pengalaman manusia ke perancangan

User merupakan objek yang penting didalam pengembangan dan pembangun sistem .User disini adalah pribadi,organisasi, dan masyarakat. User saat ini harus berada pada level of design sophistication dari semua antar muka grafis beserta isi webnya. Pada saat user berinteraksi dengan sistem user harus merasa sesuai dengan pengalaman yang pernah dirasakan dengan informasi yang disediakan oleh sistem dan merasa nyaman saat berintraksi dengan system(Sihombing et al., 2020) .

(Sumber : Wijang Widhiarso, jessianti dan sutini. Metode UCD (User Centered Design) Untuk Rancang Kios Informasi Studi Kasus: Rumah sakit Bersalin XYZ. volume 3 nomor 3,oktober 2007.)

2. Defenisi UCD (User Centered Design)

UCD adalah metode yang mendekatkan kepada kehendak user / pengguna. Ini dimaksudkan agar suatu pengembangan software sesuai dengan apa yang dikehendaki oleh pengguna. UCD adalah lebih dari sekedar membuat produk yang berguna. Menjelaskan tentang metode User Centered Design secara lebih terperinci yaitu :

1. Metode pengembangan system software

2. Metode pengembangan system interaktif

3. Pendekatan desain user-centered

4. Pendekatan desain IMK

( Sumber : Nora Yunita, S.kom, Yesi Novaria Kunang, ST M. Kom , Fatmawati, M.kom. Sistem Informasi Penjualan Online Menggunakan Metode User Centered Design (UCD) Studi Kasus :Bukit Lecha Palembang).

\section{A. Perancangan}

\section{HASIL DAN PEMBAHASAN}

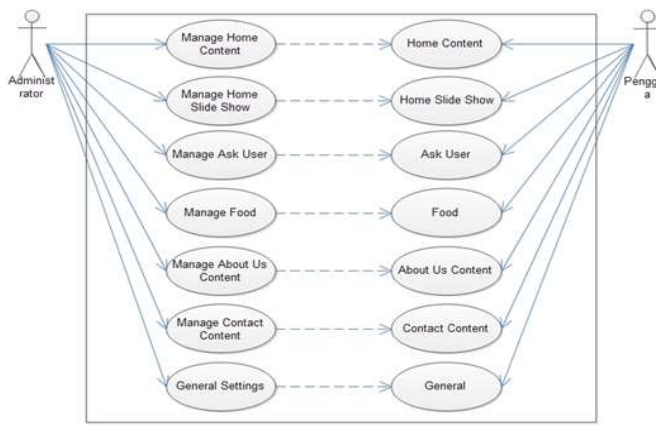

Gambar.1.Use Case Diagram Aplikasi Wisata Kuliner

\section{B. Pembahasan}


1. Analisis Metode UCD

Metode user centered design merupakan sebuah metode yang menggambarkan kebutuhan fungsional dari aplikasi yang dirancang, berikut adalah analisa metode UCD dalam perancangan web wisata kuliner kota medan

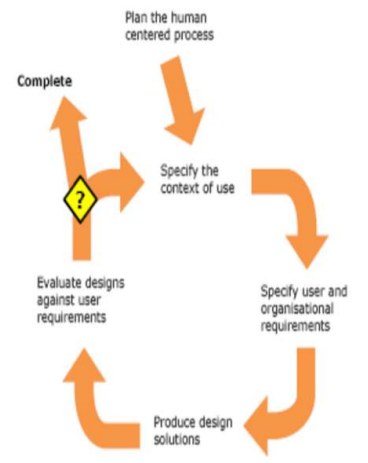

Gambar 2. Proses UCD berdasarkan ISO

Keterangan gambar :

Dari penjelasan analisa metode UCD diatas maka dapat diambil kesimpulan pada perancangan web kuliner kota medan adalah sebagai berikut:

1. Pengembangan metode UCD dapat terbantu dengan menggunakan teknik, metode, tools ,prosedur dan proses

2. Perancangan harus berhugungan lansung dengan pengguna sesungguhnya ,tujuannya adalah untuk memahami kognisi, karakter dan sikap pengguna serta karakteristik

3. Dalam perancangan sistem pengguna membutuhkan observasi tentang kelakuan pengguna misalnya, evaluasi umpan balik untuk pemecahan terhadap masalah yang ada

4. Bahasa pemrograman yang digunakan adalah PHP dan MySQL

5. Dalam penelitian ini penulis mengumpulkan data dengan cara mengunakan metode pengumpulan data dan metode pengolahan data.

Tabel.1 Analisis Metode

\begin{tabular}{|c|l|l|}
\hline No & \multicolumn{1}{|c|}{ Nama Fungsi } & \multicolumn{1}{c|}{ Keterangan } \\
\hline 1 & Menu Utama & $\begin{array}{l}\text { Menampilkan halaman dari menu utama yang } \\
\text { dirancang }\end{array}$ \\
\hline 2 & Username & $\begin{array}{l}\text { Menampilkan login untuk memasukkan } \\
\text { username yang dirancang }\end{array}$ \\
\hline 3 & password & $\begin{array}{l}\text { Menampilkan login untuk memasukkan } \\
\text { password yang dirancang }\end{array}$ \\
\hline 4 & Pengaturan Home Content & $\begin{array}{l}\text { Menampilkan, mengubah informasi home } \\
\text { content }\end{array}$ \\
\hline 5 & $\begin{array}{l}\text { Pengaturan Home Slide } \\
\text { Show }\end{array}$ & $\begin{array}{l}\text { Menampilkan, mengubah informasi gamba slide } \\
\text { show halaman website }\end{array}$ \\
\hline 6 & Pengaturan Ask User & $\begin{array}{l}\text { Menampilkan, menghapus informasi pesan } \\
\text { masuk dari user }\end{array}$ \\
\hline 7 & Manage Food & $\begin{array}{l}\text { Menampilkan, mengubah, menambah, } \\
\text { menghapus informasi makanan }\end{array}$ \\
\hline 8 & Manage About Us Content & $\begin{array}{l}\text { Menampilkan, mengubah informasi mengenai } \\
\text { penulis }\end{array}$ \\
\hline 9 & Manage Contact Content & Menampilkan, mengubah informasi kontak \\
\hline 11 & General Settings & $\begin{array}{l}\text { Menampilkan, mengubah informasi pengaturan } \\
\text { umum }\end{array}$ \\
\hline
\end{tabular}




\section{Implementasi Sistem}

1. Tampilan Form Login

Desain Halaman Utama

Desain halaman utama berisi semua tampilan utama program aplikasi informasi website kuliner kota medan

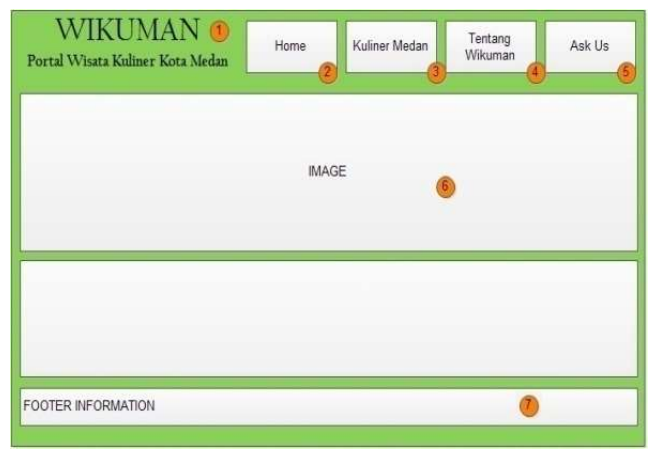

Gambar 3. Desain Halaman Utama Web

Adapun keterangannya sebagai berikut:

1. Menampilkan logo dari website wikuman yang dirancang

2. Tombol home digunakan untuk kembali ke halaman utama

3. Tombol kuliner kota medan digunakan untuk menampilkan daftar kuliner kota medan

4. Tombol tentang wikuman digunakan untuk menampilkan informasi apa itu website wikuman

5. Tombol ask us digunakan untuk menampilkan buku tamu untuk memberikan kritik dan saran

6. Menampilkan banner slide image yang berisi makanan khas kota medan dan Menampilkan informasi umum tentang kuliner

7. Footer untuk menampilkan informasi mengenai pembuat system

2. Desain Halaman Kuliner Medan

Desain halaman kuliner medan menampilkan informasi produk makanan khas kota medan, berikut desainnya

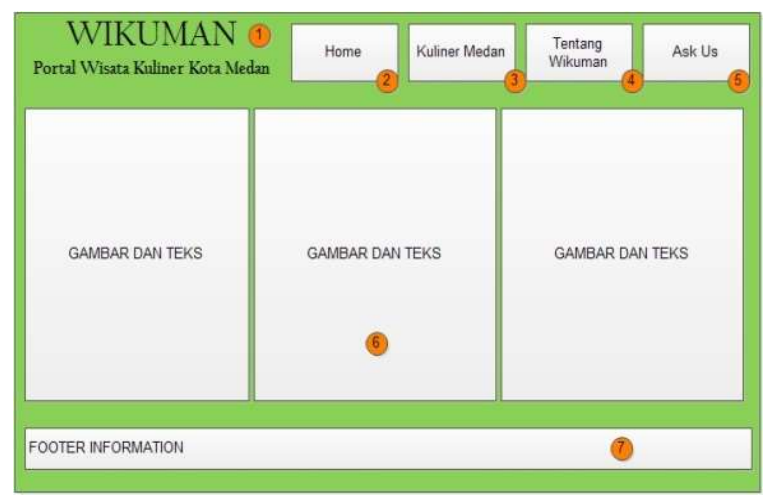

Gambar 4 Desain Halaman Informasi Kuliner Medan

Adapun keterangannya sebagai berikut:

1. Menampilkan logo dari website wikuman yang dirancang

2. Tombol home digunakan untuk kembali ke halaman utama

3. Tombol kuliner kota medan digunakan untuk menampilkan daftar kuliner kota medan 
4. Tombol tentang wikuman digunakan untuk menampilkan informasi apa itu website wikuman

5. Tombol ask us digunakan untuk menampilkan buku tamu untuk memberikan saran dan kritik

6. Menampilkan gambar dan teks mengenai kuliner kota medan.

7. Footer untuk menampilkan informasi mengenai pembuat system

3. Desain Halaman Tentang Wikuman

Desain halaman tentang wikuman digunakan untuk menampilkan informasi mengenai website wikuman, berikut desainnya.

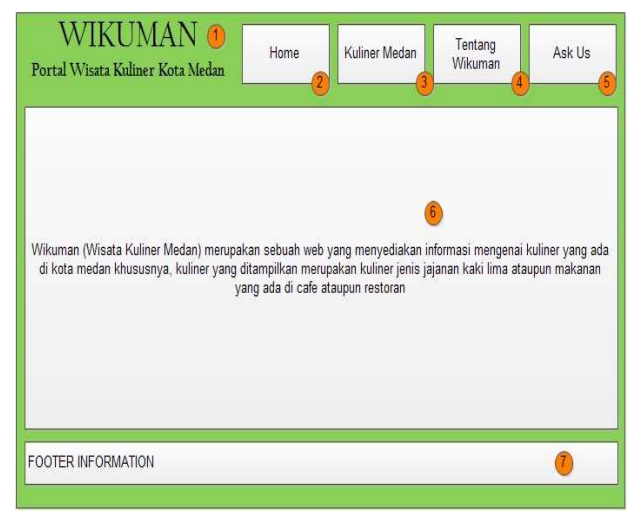

Gambar 5 Desain Halaman Tentang Wikuman

Adapun keterangannya sebagai berikut:

1. Menampilkan logo dari website wikuman yang dirancang

2. Tombol home digunakan untuk kembali ke halaman utama

3. Tombol kuliner kota medan digunakan untuk menampilkan daftar kuliner kota medan

4. Tombol tentang wikuman digunakan untuk menampilkan informasi apa itu website wikuman

5. Tombol ask us digunakan untuk menampilkan buku tamu untuk memberikan saran dan keritik

6. Menampilkan informasi mengenai website wikuman

7. Footer untuk menampilkan informasi mengenai pembuat sistem.

4. Desain Halaman Ask Us

Desain halaman halaman ask us digunakan untuk menampilkan informasi text isian untuk memasukkan kritik dan saran, berikut tampilannya.

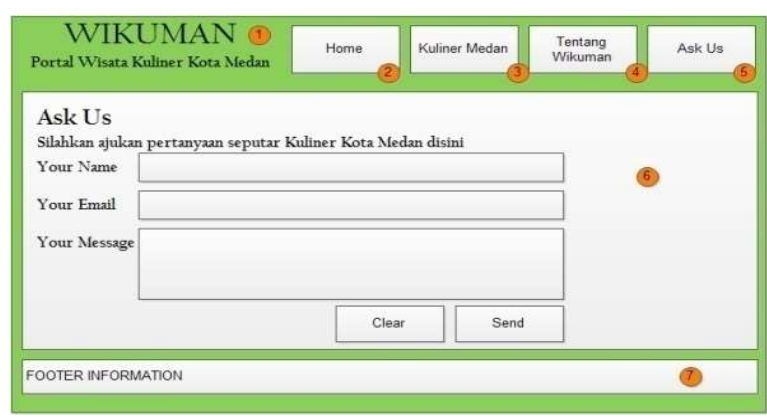

Gambar 5. Desain Halaman Ask Us 
Adapun keterangannya sebagai berikut:

1. Menampilkan logo dari website wikuman yang dirancang

2. Tombol home digunakan untuk kembali ke halaman utama

3. Tombol kuliner kota medan digunakan untuk menampilkan daftar kuliner kota medan

4. Tombol tentang wikuman digunakan untuk menampilkan informasi apa itu website wikuman

5. Tombol ask us digunakan untuk menampilkan buku tamu untuk memberikan saran dan keritik

6. Textfield isian untuk memasukkan kritik dan saran

7. Footer untuk menampilkan informasi mengenai pembuat sistem.

\section{KESIMPULAN}

Dari hasil penelitian yang dilakukan didapatkan hasil bahawa perancangan web kuliner kota medan adalah sebagai berikut:

1. Pengembangan metode UCD dapat terbantu dengan menggunakan teknik, metode, tools ,prosedur dan proses

2. Perancangan harus berhugungan lansung dengan pengguna sesungguhnya ,tujuannya adalah untuk memahami kognisi, karakter dan sikap pengguna serta karakteristik

3. Dalam perancangan sistem pengguna membutuhkan observasi tentang kelakuan pengguna misalnya, evaluasi umpan balik untuk pemecahan terhadap masalah yang ada

4. Bahasa pemrograman yang digunakan adalah PHP dan MySQL

5. Dalam penelitian ini penulis mengumpulkan data dengan cara mengunakan metode pengumpulan data dan metode pengolahan data.

\section{DAFTAR PUSTAKA}

[1] Banjarnahor, J., \& Lim, A. X. (2020). Aplikasi Pembayaran Uang Kuliah Pada Universitas Prima Indonesia Menggunakan Metode Fuzzy Logic Berbasis Android. 2(1), 7-13.

[2] Butar-butar, D. A., Amalia, D., Mayra, K., Nst, A., \& Naibaho, Y. (2020). Pemanfaatan Teknologi Informasi Dalam Pengambilan Keputusan Penilaian Karyawan Terbaik. 2(1), 43-46.

[3] Fau, A., Mesran, \& Ginting, G. L. (2017). Analisa Perbandingan Boyer Moore Dan Knuth Morris Pratt Dalam Pencarian Judul Buku Menerapkan Metode Perbandingan Eksponensial ( Studi Kasus: Perpustakaan STMIK Budi Darma ). Jurnal Times (Technology Informatics \& Computer System).

[4] Fricles Ariwisanto Sianturi, Jonson Manurung, R. F. S. (2020). LOYALTY ASSESSMENT OF COMPANY COSTUMER WITH. Jurnal Infokum, 9(1), 21-30.

[5] Fricles Ariwisanto Sianturi. (2013). Perancangan Aplikasi Pengamanan Data Dengan Kriptografi Advanced Encryption Standard ( AES). Pelita Informatika Budi Darma, 4(1), 42-46. http://ejurnal.stmik-budidarma.ac.id/index.php/pelita/article/view/208

[6] Iqbal, M. A., \& Rosnelly, R. (2020). Perancangan Aplikasi Media Pembelajaran Pengenalan Lapisan Bumi Menggunakan Augmented Reality Berbasis Android. Jurnal Mahasiswa Fakultas $\quad$..., 3(2), 26-33. $\quad$ http://e-journal.potensiutama.ac.id/ojs/index.php/FTIK/article/view/935

[7] Mikrokontroler, A., Gulo, D., Careful, G., Tumanggor, H. Y., \& Azmi, F. (2020). Rancang Bangun Robot Lengan Untuk Deteksi Warna Berbasis. 3(2), 91-95.

[8] Sihombing, O., Nainggolan, N. S., Gaol, B. L., \& Kesuma, N. (2020). Rancang Bangun Aplikasi Objek Wisata Kabupaten Tapanuli Tengah Berbasis Android. 2(1), 14-17.

[9] Zulfikar, W. B., \& Lukman, N. (2016). PERBANDINGAN NAIVE BAYES CLASSIFIER DENGAN NEAREST NEIGHBOR UNTUK IDENTIFIKASI PENYAKIT MATA. Jurnal Online Informatika. https://doi.org/10.15575/join.v1 i2.33 